\title{
Noise Levels and Noise Perception from Small and Micro Wind Turbines
}

Jennifer Taylor $_{\mathrm{a}}$, Carol Eastwick $\mathrm{a}$, Claire Lawrence $_{\mathrm{b}} \&$ Robin Wilson $_{\mathrm{c}}$

a Thermofluids Research Group, Energy and Sustainability Research Division, Faculty of Engineering b Personality, Social Psychology and Health (PSPH) Group, School of Psychology

c Architecture and Urbanism Research Division, Faculty of Engineering

(a-c) all within University of Nottingham, University Park, Nottingham, NG7 2RD

\section{Corresponding Author}

Carol Eastwick, Faculty of Engineering, University of Nottingham, University Park, Nottingham, NG7 2RD UK, email: carol.eastwick@ nottingham.ac.uk

\begin{abstract}
Noise concerns frequently pose a barrier to widespread implementation of wind turbines and while the perception of noise from large turbines has been investigated, there is a relative gap in the research for small and micro wind turbines. This paper presents findings from interdisciplinary research linking noise measurements from small wind installations with an investigation into the effect of individual personality traits and noise perception. A survey distributed to households living close to one of twelve micro or small turbine sites, coupled with environmental noise measurements was analysed. The survey showed that the most commonly perceived noises are 'swooshing' and 'humming', the presence of which may be inferred from the measured frequency spectra. Exploration of survey results showed individuals with a more negative attitude to wind turbines perceive more noise from a turbine located close to their dwelling and those perceiving more noise report increased levels of general symptoms. Individuals' personality also affected attitudes to wind turbines, noise perception from small and micro turbines and symptom reporting.
\end{abstract}




\section{Keywords}

Wind turbine, Noise, Urban, human perception, measurement

\section{INTRODUCTION}

\subsection{Background}

Noise concerns frequently pose a barrier to widespread implementation of wind turbines [1]. In the case of small and micro turbines there is limited work available in the open literature that quantifies the problem, especially in the context of an urban environment. Planning applications for small and micro wind are often contested by the general public even though there is limited understanding of the actual noise levels that are likely to be produced [2].

Whilst there is considerable research on large scale turbine noise, as evidenced by the biennial INCE/Europe Wind Turbine Noise Conferences, research related to large scale turbines cannot be directly applied to micro and small turbines. This is due to the fact that different scale turbines exhibit different noise characteristics due to rotor, mast sizes and rotational speed differences with a comparison of characteristics for different sized turbines shown in Table 1. In addition small wind systems are generally sited closer to where people live and work, often in highly populated areas and so potentially create more noise issues for individuals living nearby.

The work in this paper summarises findings from a project [3] that measured the noise levels from small and micro turbines from a number of sites close to residents and workers from whom responses to noise were sought. By relating the sound measurements and people's reactions in a rigorous manner the much debated "wind turbine syndrome" [4] can be systematically investigated. 


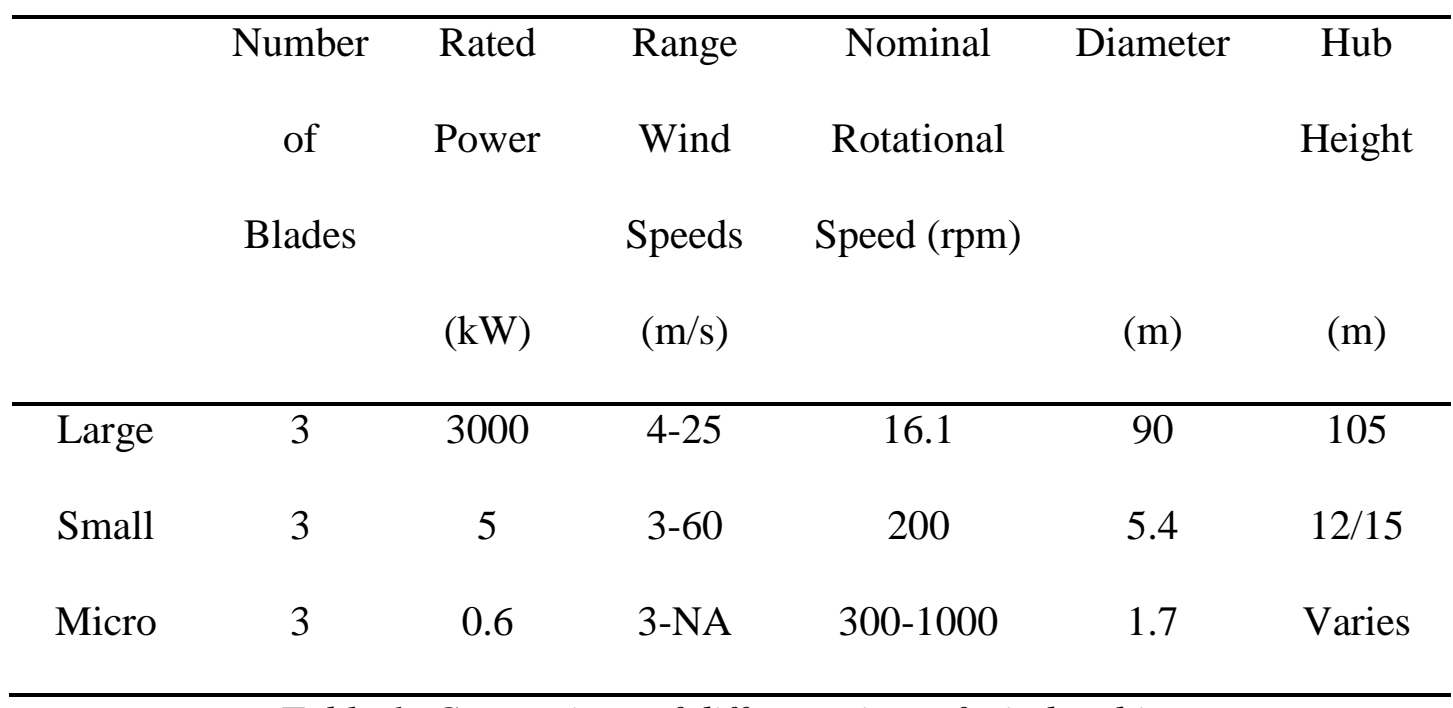

Table 1: Comparison of different sizes of wind turbine

After a summary of previous related work, this paper presents the methodology used in surveying and analysing the response of people living and working close to the turbine installations in section 2, with findings from the survey given in section 4. To understand the noise levels experienced by the respondents, environmental noise measurements were made and the methodology for this is provided in sections 3, with the data from the measurements, combined with the analysis used to calculate noise levels for locations, presented in section 5. Section 6 then draws together the noise measurements and the responses received from the survey.

\subsection{Previous Work}

Knopper and Ollson [5] provide a critical review investigating linkages between wind turbine noise and human health, covering both peer-reviewed articles and popular literature. This review highlighted the differences between peer-reviewed articles and popular literature but concluded that both state that wind turbines can be a source of annoyance to some people. Reported health effects were concluded to be statistically associated with wind turbine noise sound pressure levels over $40 \mathrm{db}(\mathrm{A})$, but with significant linkage to other factors such as visual impact, attitude to wind turbines and sensitivity to noise. This review is based on a body of research relating to large turbines but does provide a basis for investigations for other turbine sizes. The papers described below provide more detail on key papers relating to research carried out for wind turbine farms and impact on human health. 
Waye and Ohrstrom [6] evaluated annoyance due to different types of sounds from five different wind turbines ranging from $250 \mathrm{~kW}$ to $600 \mathrm{~kW}$ rated power. They stated that previous research into perception of, and annoyance due to, wind turbine noise was limited, and that the work that did exist suggested there was a weak relationship between noise levels and annoyance. In their work it was hypothesised that the different wind turbine noise mechanisms may provoke different levels of noise annoyance depending on mechanism characteristics. This is an important point to consider because, as suggested by Waye and Ohrstrom, when speculating on the broader implications of their work, it might be expected that the spectral and temporal noise characteristics of small wind turbines will vary considerably depending on the turbine type. Waye and Ohrstrom also suggested that a tonal and/or high frequency noise may be considered more annoying than a continuous sound, and sounds such as 'swooshing' were considered the most intrusive. This finding was supported in a later paper by Pederson [7] who reviewed the knowledge to date on noise perception and annoyance from large wind turbines. In this paper it was also found that people who were annoyed by wind turbine noise were also found to be the most prone to annoyance in general. Pedersen \& Waye subsequently published a sequence of papers studying human response to noise from wind turbines in Sweden [8-10], the last reference also drawing on research from Van Den Berg [11] from the Netherlands. This body of work provides the basis of Knopper \& Ollson's [5] review conclusion regarding the link between sound pressure levels and annoyance. Van den Berg subsequently published a paper [12] which summarises a chapter from Bowlder \& Leventhall's Wind Turbine Noise text [13]. Van den Berg [12] concludes that wind turbine noise, when compared to other major noise sources, is a relatively disturbing sound, ascribing unpredictability and lack of control as triggers for annoyance.

Although not specific to wind turbines, this conclusion is supported by other work, such as that by Weinstein who investigated the role of individual differences and personality on noise annoyance [14]. Weinstein found that people who tend to be consistently negative were typically more annoyed by a new source of noise. In addition, there have been studies exploring community noise levels, which have examined individual differences in terms of stress and coping [15] as well as studies linking annoyance to traffic noise. For example, Belojevic et al. investigated subjective reactions to annoyance from 
traffic noise as a function of personality traits [16]. It was found that noise sensitivity and neuroticism significantly and positively influenced the extent to which participants found traffic noise annoying. Therefore in the current study it is important that personality characteristics are recorded when surveying for reaction to noise.

Even if the noise attributed to micro and small wind turbines is of a low level, as Pedersen and Waye [17] surmise, in a society with an increasing noise load, even low level noise, may be perceived as annoying. The importance of environmental noise measurements taken in the field at real turbine installations is evident from this comment. Quantifying the actual noise levels and associated frequency characteristics of small and micro turbines provides a context against which to compare the responses of subjects. Measurement provides an objective description to both inform the methodology for exploring the subjective response of participants in the survey and interpreting the subsequent results.

Devine-Wright [18] concluded that much of the existing research examining wind turbine noise has focused on rural, upland, wind-farms and there is a gap in the body of research for smaller-scale and building integrated wind turbines in urban areas. Also stated in Devine-Wright's conclusions is that no attempt has been made to establish the underlying causes of psychological processes related to the perception of wind turbine noise and the effect of this noise on individuals' health. The current paper summarises work which addresses this key area of smaller scale wind turbines and impact on human health.

\section{THE ROLE OF INDIVIDUAL DIFFERENCES ON THE PERCEPTION OF NOISE}

Households living within $500 \mathrm{~m}$ to one of twelve micro or small wind turbine installations were contacted to participate in the study, where turbine sites were chosen because they crossed a number of social and geographical regions. All households (number contacted $=1327$ ) were sent a survey by postal mail. Any member of each household over the age of 18 could anonymously complete the survey, returning their response by postal mail or via the internet. Of the 1327 households contacted, 57 were returned without being completed due to out of date address details. There were 138 completed returns meaning a satisfactory response rate of $10.86 \%$. 


\subsection{Survey}

\section{Section One}

The first section of the survey was designed to measure the level of noise intrusion experienced by participants and to rate their general attitude towards wind power.

Participants were asked to rate, on a seven point Likert scale, their attitude to wind power in general (1 $=$ very positive, $7=$ very negative). They were also asked to state whether they could see a turbine from their residence and whether there was a turbine attached to their own residence.

For noise intrusion, participants were asked to identify how often (occurrence) they heard ten types of sounds (listed in section 4, table 2) from the turbine near their dwelling and how loud (loudness) the sounds were when they did hear them. All ratings were taken on a five point scale $(0=$ rarely or never, 5 $=$ all the time). In addition participants were asked to report at which times of day and in what weather conditions (e.g. wind, rain, and sunshine) they typically noticed the ten sounds.

\section{Section Two}

Section two of the questionnaire consisted of measures of individual differences and mood.

Frustration intolerance was measured using a 14-item adapted version of the Frustration Discomfort Scale [19]. This scale measures an individual's inability to cope with distressing stimuli (e.g. noise, difficult emotions, etc). Respondents were asked to rate on a five point Likert scale the degree to which they experienced intolerance of negative stimuli. The questions measured two components: discomfort intolerance (e.g. 'I can't stand to do task when I'm not in the mood') and emotional intolerance (e.g. 'I can't stand situations where I might feel upset'). The internal reliability of each of these subscales was tested by examining the Cronbach's Alpha and were found to be good: a Cronbach's Alpha score of 0.854 and 0.857 was obtained for discomfort intolerance and emotional intolerance respectively (a Cronbach's Alpha score value greater than 0.7 for any measure is considered good).

Frustration sensitivity was measured using the 10-item Frustration Sensitivity subscale of the Situational Triggers of Aggressive Responses (STAR) scale [20], examining individual differences in 
the extent to which individuals become aggressive as a result of frustrations (e.g. 'I hear a noise that I cannot control'). Participants indicated the extent to which statements were true for them $(1=$ very inaccurate for me, 5 = very accurate for me). The Cronbach's Alpha for this scale was 0.914 .

Neuroticism was measured with a 10-item Neuroticism scale [21] to evaluate each respondent's tendency to negative emotional states (e.g. 'I have frequent mood swings'). Neuroticism has also been associated with increased symptom reporting and poorer health [22]. Participants rated on a five point scale how well each statement applied to them $(1=$ very inaccurate for me, $5=$ very accurate for me $)$. The Cronbach's Alpha for the Neuroticism scale was 0.844 .

Trait mood was assessed using an adapted 12-item version of the Positive and Negative Affectivity Scale (PANAS) [23]. Trait positive affect (PA) refers to the extent to which a person typically feels enthusiastic, active and alert. Trait negative affect (NA) provides a measure of subjective distress and displeasure, where high negative affectivity causes feelings such as anger, contempt, and nervousness. Respondents were asked to rate on a five point scale how often they had felt 6 positive (e.g. enthusiastic, interested) and 6 negative (e.g. hostile, nervous) feelings in the previous month $(1=$ very slightly, $5=$ extremely). The results indicated Cronbach's Alpha scores of 0.933 and 0.853 for positive and negative affectivity scales respectively.

\section{Section Three}

Section three measured each participant's general health using a symptom checklist. Participants were asked to rate the extent to which they had experienced ten common symptoms (e.g. headache, breathlessness $)$ in the previous month $(0=$ not at all, $5=$ very severely). A total symptom reporting score was determined for each individual. The Cronbach's Alpha for the symptom scale was 0.846 .

\section{Section Four}

Section four sought information from participants about demographic details, (e.g. age, sex, occupation, residence type, period of residence), to enable analysis of sample homogeneity and dependence. 


\subsection{Participants}

One hundred and thirty eight people responded to the survey. Their ages ranged from 20 to 95 (mean age $=54, \mathrm{SD}=15.6), 74$ were male and 62 female (2 did not specify their sex $).$

The postal method used to collect data from participants meant that the sample population was selfselecting. It was therefore necessary to check the sample population were not all from the same societal demographic. Demographic characteristics of participants were checked and found to be representative of the relevant wider populations [24].

In addition, it was important to establish that participant self-selection was not causing a bias in the collected data, therefore a comparison of how participants from each occupation group perceived wind turbine noise, their attitudes to wind turbines and their symptom reporting was carried out, as the best means using the data available, to establish whether a bias may exist. If the mean values of attitudes noise perception and symptom reporting between each occupational group were not significantly different, then the sample population can be concluded to provide a valid representation of the overall population and the data could be analysed as one group. Three one-way between-groups ANOVA (analysis of variance) tests were conducted. An ANOVA compares the mean scores of a dependent variable for more than two groups; in this case occupation, and is so called because it does this by comparing the variance in the dependent variable between the groups with the variance within each of the groups. This is done by calculating the $F$ ratio. A significant $F$ ratio (where $p<0.05$ ) indicates that there is more variability in the dependent variable due to the independent variable between the groups rather than within the groups. In this case a non-significant effect and low $\mathrm{F}$ ratio are required to indicate that there are no differences between the occupational groups on attitudes, noise perception and symptom reporting and all participants can be analysed as one group (attitudes $\mathrm{F}_{6,110}=1.104$, $\mathrm{p}=.365$; noise perception $\mathrm{F}_{6,116}=0.733$, $\mathrm{p}=.624$; symptom reporting, $\mathrm{F}_{6,104}=1.003$, $\mathrm{p}=.427$ ).

The data show that all three statistical tests fail to reach statistical significance (i.e. $p>0.05$ for each test). Hence those in a particular occupational group did not have more negative attitudes to wind 
turbines, perceive increased noise levels or report increased symptoms of ill health. For this reason the data can be analysed as one group.

Survey results are presented in Section 4.

\section{ENVIRONMENTAL NOISE MEASUREMENT METHODOLOGY}

In order to understand the characteristics of noise from micro and small wind turbines, and the potential effects these have on those living within the vicinity, environmental noise measurements were taken. A sound level meter (Bruel and Kjaer 2260 Investigator) was used at locations selected on the basis of practicality (e.g. accessibility) and usability (i.e. useful information could be extracted by comparing data taken at different locations).

Summary results for two key sites will be reported in this paper. One micro turbine site was chosen because the turbines at this site could be switched off so comparisons at the same conditions could be made with and without the turbines running. The other site chosen for this paper was a small turbine site where the background noise is low and measurements could easily be taken at increasing distances from the turbine.

Due to the characteristics of the noise from small wind systems and the features of the siting of each turbine (often in built up areas with high levels of vehicular traffic) it was impractical to determine sound pressure levels at every single respondent's dwelling for every wind speed and direction. Ideally measurements would be taken inside and outside of every single respondents dwelling at a range of wind speeds and conditions, but this was impossible due to access constraints. The focus is therefore on the characteristics of the sounds from each turbine. The key output from the measurements are an analysis of the frequency spectra associated with small wind systems, as well as, an indication of the key frequencies of small wind system noise.

To get an overall picture of the likely levels of small wind system noise at real installations and how the noise propagates to buildings and areas near to the turbines sited at each installation, sound maps were 
created which show how sound at the measured key frequencies attenuates over the topographical area. This was carried out using the DataKustik CadnaA 4.1 software package. The CadnaA software uses the ISO 9613 standards [24, 25] "Acoustics attenuation of sound during propagation outdoors" to calculate the attenuation of sound over a topographical map.

The measurements and sound maps allow potential links between actual sound levels and sounds reported from the turbines by respondents in the survey results to be explored.

For this paper data from two installations are presented for illustration purposes. The first is an example of a micro turbine installation (Installation 1) and the second an example of a small wind turbine installation (Installation 2). Installation 1 has two $0.6 \mathrm{~kW}$ turbines mounted on the roof of an eight storey domestic tower block (figure $1 \mathrm{~T} 1 \mathrm{a} \& \mathrm{~T} 1 \mathrm{~b}$ ). The area is built up on three sides with two subsequent tower blocks and the fourth side faces onto fields. Installation 2 has two $5 \mathrm{~kW}$ turbines (figure 1 T2a \& T2b) set in a rural park with some small park buildings nearby. Wind speeds are reliable and undisturbed at this site and the turbines have access to prevailing wind across a large lake and open grassland.

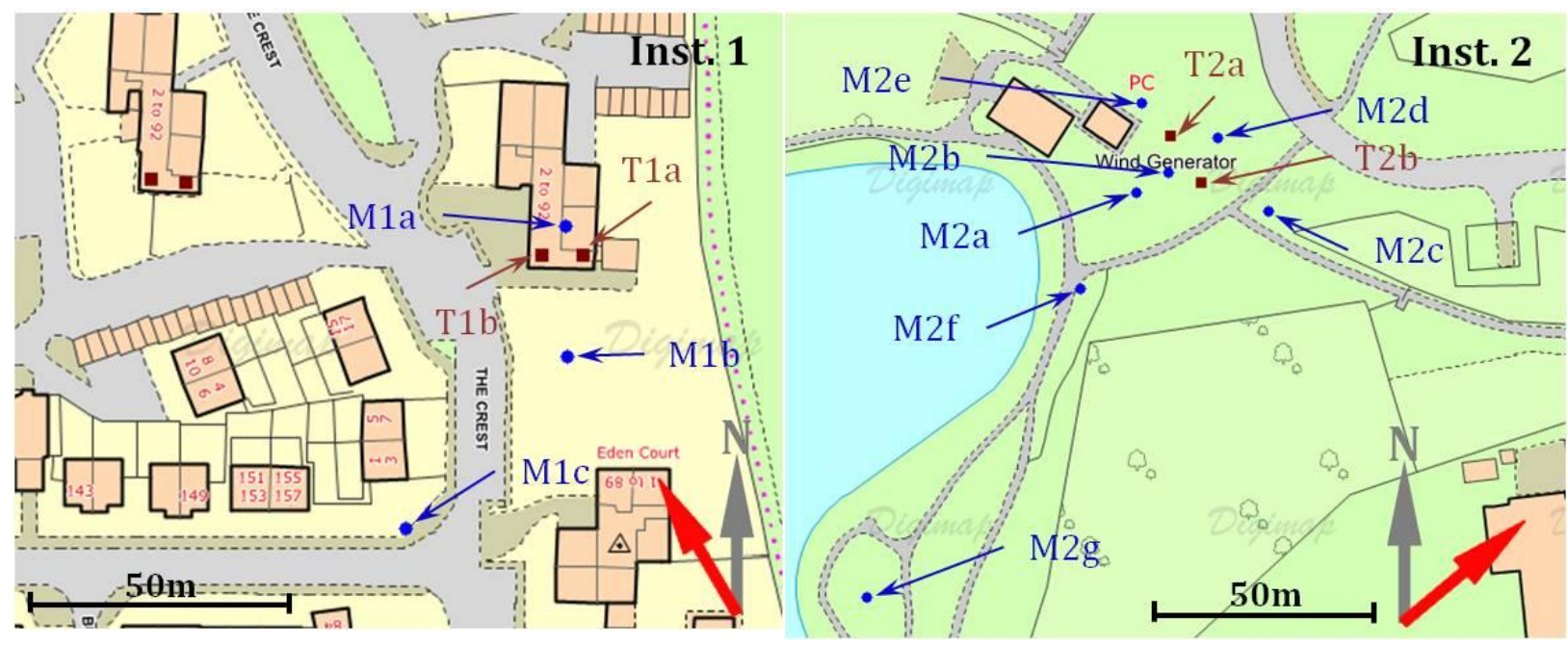


Figure 1: Maps showing the turbine locations (T) and measurement locations (M) at installations 1 and 2. Prevailing wind direction shown relative to North in bottom right of both images

For Installation 1, three measurement locations were used and are shown in Figure 1 (Inst. 1). Measurements are taken at location M1a on the roof of the tower block with the turbines on and off. There are also two measurement locations (M1b and M1c) at ground level at increasing distances from the turbines. There were seven measurement locations used at Installation 2, shown in Figure 1 (Inst. 2); four in the prevailing upwind direction at increasing distances from the turbines (M2a, M2b, M2f and M2g), with the furthest (M2g) being used to estimate background noise. The remaining three locations comprised one downwind (M2d) of the turbines and two locations at a prevailing cross wind direction to the turbines (M2c and M2e).

Data collected from these installations is presented and analysed in section 5.

\section{SURVEY RESULTS}

All survey data were analysed using the statistical package SPSS. For more details on all of the statistical methods used within this paper see [26]. The survey data are analysed as one set to explore the associations between attitudes, perceived noise and general health. To investigate the sounds that respondents reported from the turbine near their dwelling the data set is split according to the different turbine types.

\subsection{Basic characteristics of the studied population}

The majority of respondents $(64.8 \%)$ could see a turbine from their dwelling, and $14 \%$ had a turbine attached to their own building. Respondents generally reported a positive attitude to wind turbines ( mean attitude $=2.33, \mathrm{SD}=1.76$, where $1=$ very positive to $7=$ very negative). Analysing the responses it was clear that there was a higher response rate for small turbine installations (mean response drawn from four sites was $17.78 \%$, standard deviation of 2.33) compared to the micro turbine installation sites (mean response drawn from nine sites was 9.7\%, standard deviation of 5.05). The 
lowest response rate of $3.7 \%$ was for a micro turbine installation that was sited in an area of high transitory population, whereas the highest response rate of $20 \%$ was for a rural - flat area with a low number of properties situated within sight of the turbine. Overall, the response rate of $9.7 \%$ was comparable to that found elsewhere for similar surveys collected via post [27].

\subsection{Wind turbine sounds}

Table 2 shows the mean noise perception score for each of the ten sounds listed in Section 1 of the survey. The table is split into three sections to show combined scores for all installations surveyed, as well as separate results for all the $0.6 \mathrm{~kW}$ micro turbine type (installation 1 type) and all the $5 \mathrm{~kW}$ small turbine type (installation 2 type). Two scores are shown in each section, one for how often people hear the sounds (occurrence) and another for how loud they perceive each sound to be (loudness). Scores have been transformed from the original questionnaire so this means a score of 0 represents the sound never being heard where a score of 4 means the sound is heard continuously and is extremely loud when heard. 


\begin{tabular}{l|cc|cc|cc}
\cline { 3 - 6 } & \multicolumn{2}{c}{ All } & \multicolumn{2}{c}{ Micro 0.6kW } & \multicolumn{2}{c}{ Small 5kW } \\
\cline { 2 - 7 } & Loudness & Occurrence & Loudness & Occurrence & Loudness & Occurrence \\
\hline Swooshing & $0.421^{2}$ & $0.500^{1}$ & $0.588^{2}$ & $0.627^{1}$ & $0.147^{2}$ & $0.235^{1}$ \\
Screeching & 0.091 & 0.099 & 0.132 & 0.149 & 0.000 & 0.000 \\
Buzzing & 0.182 & 0.176 & $0.309^{4}$ & $0.284^{4}$ & 0.000 & 0.000 \\
Whistling & $0.244^{3}$ & $0.258^{3}$ & $0.388^{3}$ & $0.373^{3}$ & $0.030^{5}$ & $0.061^{5}$ \\
Humming & $0.429^{1}$ & $0.427^{2}$ & $0.603^{1}$ & $0.567^{2}$ & $0.152^{1}$ & $0.188^{3}$ \\
Throbbing & 0.160 & 0.152 & $0.269^{5}$ & 0.224 & $0.091^{4}$ & $0.152^{4}$ \\
Thumping & 0.091 & 0.114 & 0.176 & 0.179 & 0.000 & 0.000 \\
Scratching & 0.053 & 0.068 & 0.074 & 0.075 & 0.000 & 0.000 \\
High Freq. & $0.183^{5}$ & $0.177^{5}$ & 0.254 & $0.273^{5}$ & 0.000 & 0.000 \\
Low Freq. & $0.205^{4}$ & $0.217^{4}$ & 0.194 & 0.242 & $0.121^{3}$ & $0.212^{2}$ \\
\hline
\end{tabular}

Table 2: Mean Noise Perception Score for loudness and frequency of hearing each sound (Superscript denotes ranking)

The most commonly occurring and loudest sounds from the micro turbine type are 'humming', 'swooshing', 'whistling', 'buzzing' and 'high frequency' sounds. However, 'high frequency' and 'buzzing' sounds are not reported from the $5 \mathrm{~kW}$ turbine. The reported occurrence and loudness of all the sounds from the $0.6 \mathrm{~kW}$ turbine are higher than for the $5 \mathrm{~kW}$ turbine. Only five sounds are reported as being heard from the 5kW turbine, these are 'swooshing', humming', 'low frequency', 'throbbing' and 'whistling'. The most commonly occurring and loudest sounds from all the turbine types are 'humming', 'swooshing', 'whistling' and 'low frequency'.

The mean score for perceived noise loudness and occurrence across each of the ten sounds was calculated to give a single Noise Perception variable. This variable was positively skewed and so was transformed using square root transformation. Analyses were then conducted on the transformed variable. 


\subsection{Attitudes, symptom reporting and noise perception}

The effect of seeing a turbine from the property on perceived noise, symptom reporting and attitude to wind power was examined using three independent samples t-tests. An independent sample t-test is a statistical technique used to examine whether mean scores for the two groups of subjects (i.e. those who can and those who cannot see the turbines) are significantly different, showing that differences between the groups explain some variance in the outcome. The results are shown in table 3 .

A p-value less than 0.05 indicates a significant finding, the lower the p-value the higher the significance, as is true for any statistical test carried out. These results show that seeing a turbine from the property is associated with increased perception of noise from the turbine, but does not affect attitude or symptom reporting.

\begin{tabular}{lcc}
\hline Dependent Variable & $\mathbf{t}$ & $\mathbf{p}$ \\
\hline Noise Perception & $\mathbf{- 3 . 5 8 3}$ & $\mathbf{. 0 0 1}$ \\
Symptom Reporting & -0.411 & .682 \\
Attitude & 0.009 & .993 \\
\hline$p$ values below .05 are considered statistically \\
significant
\end{tabular}

Table 3: Results of three independent samples t-tests investigating the affects of visibility of a turbine

The extent to which the attitude to wind power influenced the perception of noise from the turbine was examined using linear regression. A linear regression is a statistical method that shows how well one or a set (multiple regression) of independent variables (the model) predicts the dependent variable. A multiple regression can also show which, if any, of the independent variables within the model offer a statistically significant contribution to the dependent variable. Beta values range between 0 and 1 , showing the individual contribution of each independent variable to the dependent variable, the highest beta values indicate the strongest contribution. 
Attitude to wind power significantly predicted noise perception (see first row in table 4) with more negative attitudes predicting increased perceived noise. To examine the extent to which the higher noise levels predicted poor health outcomes (symptoms) a second linear regression was conducted, with symptom score as the dependent variable and perceived noise as the predictor. Perceived noise significantly predicted symptom reporting, with those reporting higher noise levels from the wind turbine reporting more symptoms (see second row in table 4). When these data were analysed only considering those who reported being able to hear any sound, these relationships remained significant.

\begin{tabular}{lllc}
\hline \multicolumn{1}{c}{$\begin{array}{l}\text { Independent } \\
\text { Variable }\end{array}$} & \multicolumn{1}{c}{ Dependent Variable } & Beta & $\mathbf{p}$ \\
& & & \\
\hline Attitude & Noise Perception & .284 & .001 \\
Noise Perception & Symptom Reporting & .224 & .014 \\
\hline$p$ values below .05 are considered statistically significant &
\end{tabular}

Table 4: Results from a linear regression of attitudes, noise perception and symptom reporting

To examine the effect of participants' age, sex and personality variables on attitude to wind power, perceived noise and symptoms respectively, three hierarchical linear regressions were conducted. A hierarchical linear regression is the same as a multiple regression, except the independent variables are entered in a specific order in steps; the effects of models in the previous steps are controlled for in the subsequent steps. For each analysis, age and sex were entered at step 1, followed by the personality variables at step 2 (see table 5). The R-values show the overall contribution of the model to the independent variable at step 1 and R-square values show the contribution of the model in step 2 once the independent variables in step 1 are controlled for.

Age and sex had no effect on attitudes to wind power, noise perception or symptoms. However, adding personality into the analysis significantly added to the explained variance for the three dependant variables. Specifically, those with higher positive affectivity (PA) and those with lower negative 
affectivity (NA) were more positive to wind power and perceived less noise from the turbine. Individuals with higher Frustration Discomfort were more negative to wind turbines and those with higher intolerance to Emotional Frustrations reported increased noise from the turbine. Individuals reported more ill-health symptoms if they scored higher in NA, Neuroticism and Frustration Discomfort (see beta values in table 5 with $\mathrm{p}<0.05$ ).

When the impact on Noise Perception were analysed considering only those who perceived noise from the turbines, the relationship between negative affectivity and Noise Perception remained significant, and the influence of Frustration Sensitivity also predicted Noise Perception. Specifically, those who typically become aggressive or angry due to frustrations reported hearing more noise $($ Beta $(\mathrm{df} 8,32),=$ .403; $\mathrm{p}$ <.05). The influence of PA and Emotional Discomfort became non-significant, indicating that the most robust influence on Noise Perception was negative affect. 


\begin{tabular}{|c|c|c|c|c|c|c|}
\hline Independent & \multicolumn{6}{|c|}{ Dependent Variable } \\
\hline & \multicolumn{2}{|c|}{ Attitude } & \multicolumn{2}{|c|}{ Noise Perception } & \multicolumn{2}{|c|}{ Symptoms } \\
\hline & Beta & $p$ & Beta & $p$ & Beta & $p$ \\
\hline \multicolumn{7}{|l|}{ Step 1} \\
\hline Age & .232 & .018 & -.111 & .250 & .054 & .577 \\
\hline \multirow[t]{2}{*}{ Sex } & .020 & .833 & -.005 & .958 & .060 & .535 \\
\hline & \multicolumn{2}{|c|}{$\mathrm{R}=.231$} & \multicolumn{2}{|c|}{$\mathrm{R}=.111$} & \multicolumn{2}{|c|}{$\mathrm{R}=.078$} \\
\hline \multicolumn{7}{|l|}{ Step 2} \\
\hline Age & .191 & .039 & -.097 & .276 & .088 & .313 \\
\hline Sex & .022 & .804 & -.024 & .779 & .081 & .328 \\
\hline PA & -.427 & .000 & -.342 & .001 & .023 & .810 \\
\hline NA & .382 & .000 & .446 & .000 & .204 & .037 \\
\hline Neuroticism & -.104 & .396 & -.122 & .307 & .410 & .001 \\
\hline FD Discomfort & .316 & .031 & -.178 & .210 & .366 & .009 \\
\hline FD Emotional & -.142 & .392 & .348 & .034 & -.158 & .314 \\
\hline \multirow[t]{2}{*}{ STAR Frustration } & -.054 & .591 & -.080 & .414 & -.038 & .691 \\
\hline & \multicolumn{2}{|c|}{ R Square $=.290^{* * *}$} & \multicolumn{2}{|c|}{$\mathrm{R}$ Square $=.282^{* * *}$} & \multicolumn{2}{|c|}{ R Square $=.325^{* * *}$} \\
\hline
\end{tabular}

Table 5: Affect of personality variables on attitude, noise perception and symptom reporting

\subsection{Survey Conclusions}

The results show that if a respondent can see a small wind turbine installation from their dwelling they report higher and more frequent noise levels from that turbine. There could be two reasons for this; the first reason is that the respondents who can see a turbine are those living closest to the turbine installation so are more likely to perceive the noise as there are less barrier objects between the source 
and the receiver. However, secondly, there have been studies [12,28] suggesting that the visibility of a noise source increases the likelihood of reporting noise from that noise source compared to not being able to see the noise source at the same sound pressure levels.

It is interesting to note from table 3 that those who can see a turbine from their dwelling do not have a significantly more negative attitude to wind turbines. Some objections have been made to wind turbine installations due to the aesthetics of turbines and for example, shadow flicker. This, however does not appear to be the case here; whether or not an individual can see a wind turbine from their dwelling does not affect their attitudes, nor does it result in increased levels of symptom reporting.

Table 4 shows that those with a more negative attitude to wind turbines report louder and more frequent noise $(\mathrm{p}<0.05)$ from the wind turbine close to their dwelling. However, the direction of this relationship cannot be established from these results. There are two explanations for this finding:

- Individuals who have a negative attitude to wind turbines report noise from micro/small turbines located near them because they are sensitised to the noise.

- Individuals who hear louder and more frequent noise from the small turbine near them have a more negative attitude to wind turbines due to this noise.

Taken together, the results also represent a body of evidence to demonstrate the potential route by which wind turbines may affect the health of individuals in their proximity. First, trait positive and negative affectivity influence attitude to wind power. Attitude to wind power, in turn, together with negative and positive affectivity, influence how loud the turbine is perceived to be. This perception of noise together with negative affectivity, Neuroticism and Frustration Discomfort influences ill-health symptoms. Therefore it is important to note that any link between living near wind turbines and ill health may well be, at least in part, accounted for by the personality of the individual, as this personality has been shown here to influence the attitude to wind power, the perceived noise from the turbine and level of symptoms experienced. This has not been demonstrated elsewhere in the literature. 
This linkage between personality traits, perceived noise and level of symptoms reported is investigated in more detail in a separate paper [29].

\section{ENVIRONMENTAL NOISE MEASUREMENTS RESULTS}

At installation 1 where two micro wind turbines are mounted on the roof of a tower building (see Figure 1 (Inst. 1)) environmental noise measurements were taken at measurement location M1a, in the same conditions with the turbines switched on and off. The frequency spectra associated with these measurements can be seen in Figure 2. When the turbines are switched on, sound levels are higher at all frequencies. However, differences are small below $100 \mathrm{~Hz}$. Wind noise is assumed constant for measurements taken with both the turbines on and off as they are taken in the same conditions, where wind speed and direction data are sufficiently similar between measurements with turbines on and off. This illustrates that the turbines add to the background noise at all frequencies in the spectrum.

The background noise at Installation 1 is low; it occurs mostly due to a low level of human activity, trees and birds. There is a peak in the turbine spectrum at around $160 \mathrm{~Hz}-500 \mathrm{~Hz}$, which is higher than the blade pass frequency mechanism, so could be due to mechanical noise at the turbine hub as a result of electro-mechanical equipment. At the highest frequencies a large difference can be seen between the two sets of data with the turbines increasing the $\mathrm{L}_{\text {Aeq }}$ by almost $20 \mathrm{~dB}(\mathrm{~A})$ at $10 \mathrm{kHz}$ (reference sound pressure value $2 \times 10^{-5} \mathrm{~Pa}$ for all values). The range of frequencies for normal human hearing is from $20 \mathrm{~Hz}$ to $20 \mathrm{kHz}$. The typical noise levels inside a living room, bedroom or quiet office are approximately $40 \mathrm{~dB}$. 


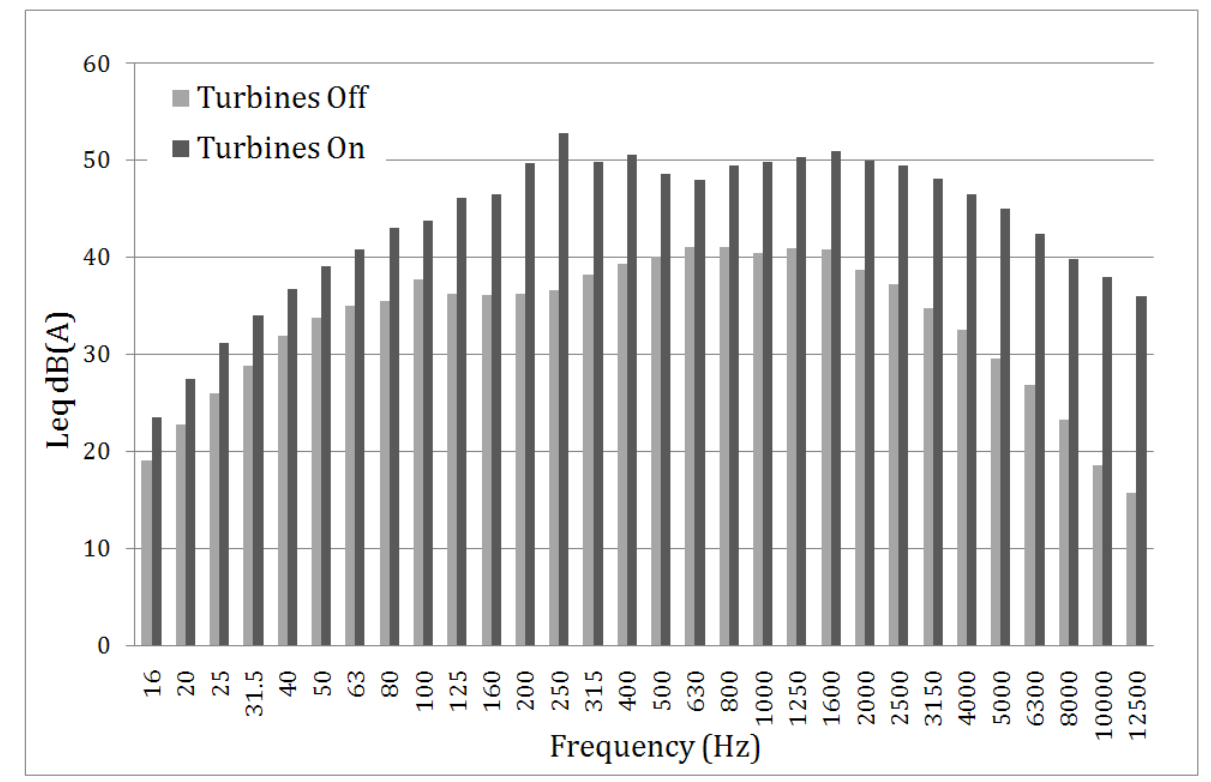

Figure 2: LAeq comparisons with turbines on and off at Installation 1 at $7 \mathrm{~m} / \mathrm{s}$ wind speed 
Measurements taken at Installation 2 at increasing upwind distances, for wind speeds of $7 \mathrm{~m} / \mathrm{s}$ and $12 \mathrm{~m} / \mathrm{s}$, are shown in Figure 3 and Figure 4 respectively. Wind data was collected on site for the duration of the measurements to verify that wind speed and direction remained constant.

At low frequencies there is little dependence on proximity to the turbines, suggesting that low frequency differences to the data are dominated by background noise (including wind noise). Frequencies above $125 \mathrm{~Hz}$ do show a significant dependence of sound levels on proximity to the turbines with significant increases closer to the turbines above $1250 \mathrm{~Hz}$. These phenomena are visible on the $7 \mathrm{~m} / \mathrm{s}$ and $12 \mathrm{~m} / \mathrm{s}$ wind speed measurement data. A peak also occurs in both the $7 \mathrm{~m} / \mathrm{s}$ and $12 \mathrm{~m} / \mathrm{s}$ spectra in the bands between $160 \mathrm{~Hz}-400 \mathrm{~Hz}$. The location of the peak shows a dependency on the wind speed and at higher wind speeds when the turbine rotates slightly faster the peak occurs at a slightly higher frequency. This peak is again too high to correspond to the blade pass frequency, therefore is likely to be due to mechanical or electromechanical noise.

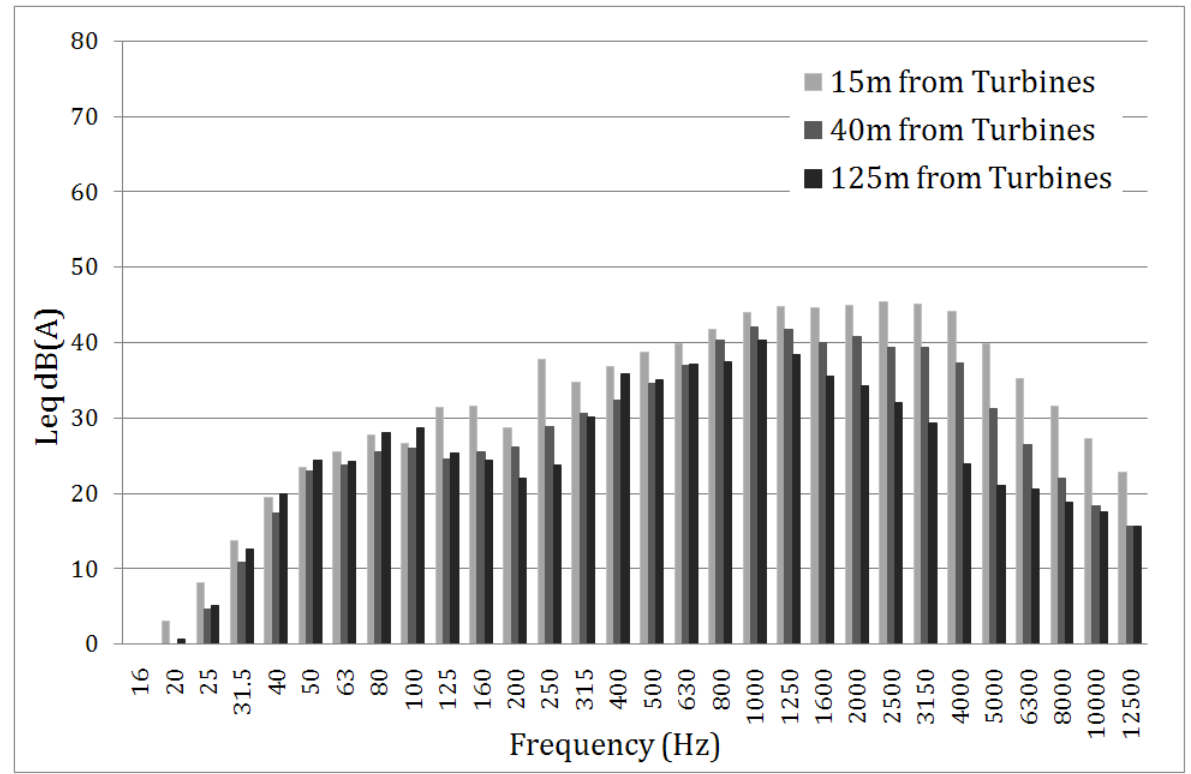

Figure 3: $L_{\text {Aeq }}$ at increasing distances upwind from turbines at Installation 2 at $7 \mathrm{~m} / \mathrm{s}$ wind speeds 


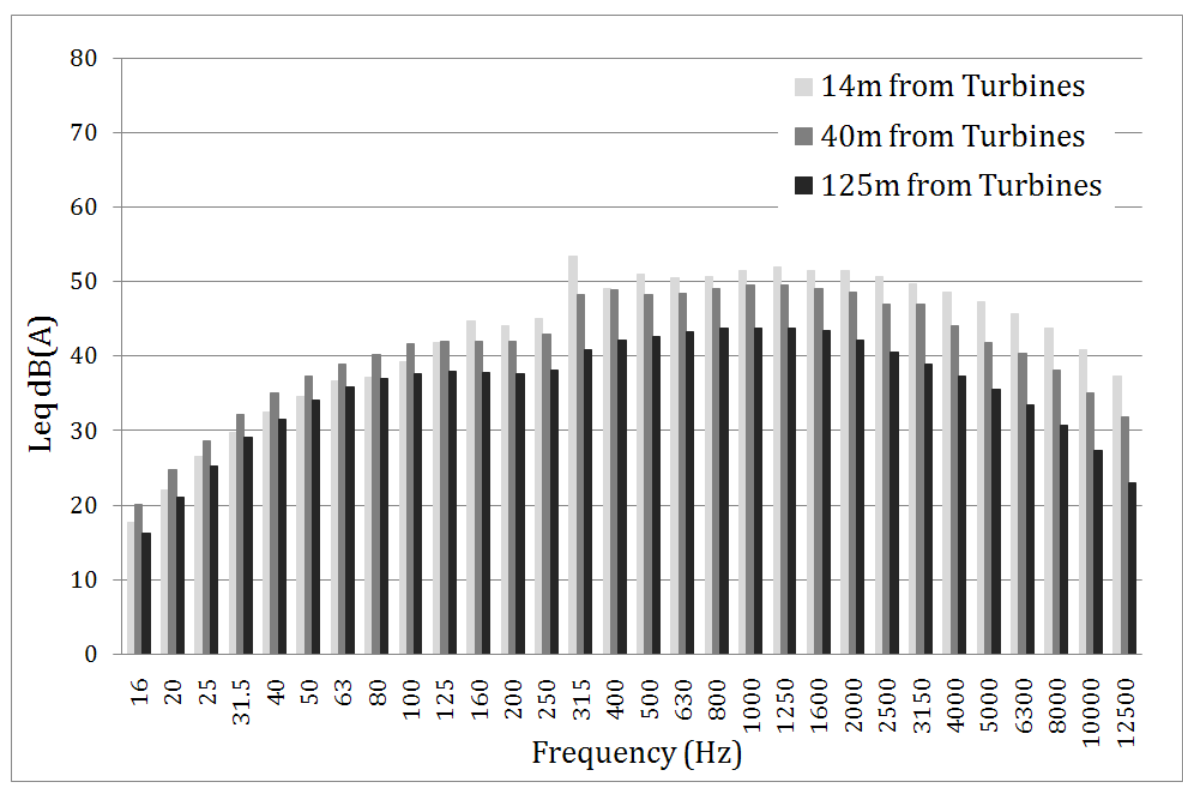

Figure 4: $L_{\text {Aeq }}$ at increasing distances upwind from turbines at Installation 2 at $12 \mathrm{~m} / \mathrm{s}$ wind speed

In order to relate the sound measurements to a typical sound level from a turbine for a household sound maps have been created. Analysis of how the sound from the turbine at each installation attenuates across the surrounding geographical area was calculated using a series of geographical 'sound maps' generated with the DataKustik CadnaA software package as described in section 3. Figure 5 shows a typical 'sound map' highlighting the three regions used for analysis of actual sound, where region 0 had a low probability and region 2 a high probability of hearing the turbine. These regions were then utilised to analyse perceived versus actual noise levels [29].

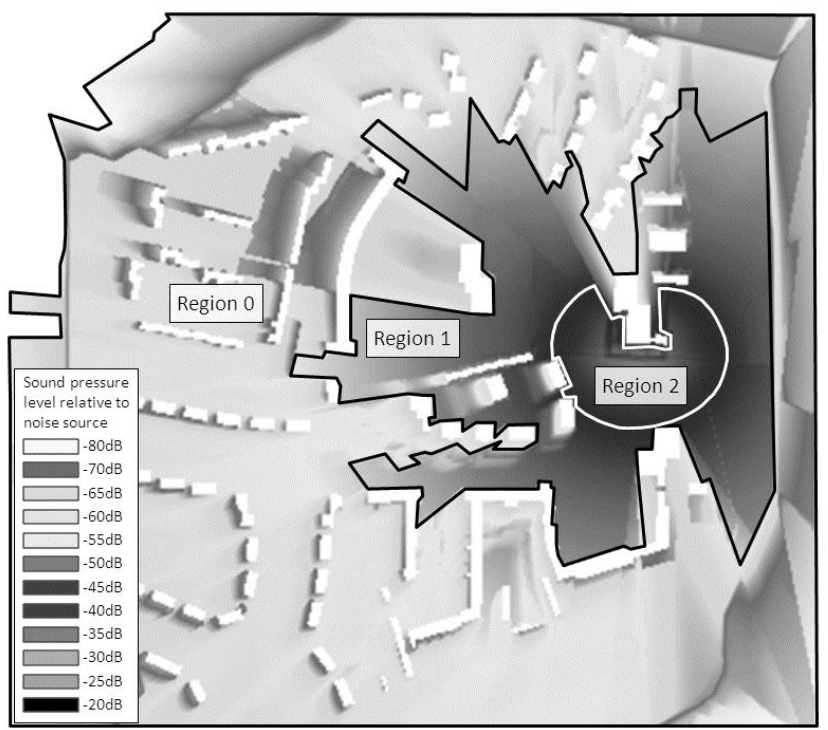


shown highlight sound pressure levels relative to the noise source.

\section{REPORTED SOUNDS AND FREQUENCY SPECTRA}

In this section of the paper comparisons will be made between the commonly reported sounds from results of the survey and the measured frequency spectra from environmental noise measurements at the two previously described installation.

The $\mathrm{L}_{\text {Aeq }}$ of a 2 minute sample taken at Installation 2 at a distance of $14 \mathrm{~m}$ from the turbines at $12 \mathrm{~m} / \mathrm{s}$ wind speeds was $63.2 \mathrm{~dB}(\mathrm{~A})$, for $7 \mathrm{~m} / \mathrm{s}$ wind speeds the $\mathrm{L}_{\text {Aeq }}$ was $54.4 \mathrm{~dB}(\mathrm{~A})$. At Installation 1 the $\mathrm{L}_{\mathrm{Aeq}}$ at $7 \mathrm{~m} / \mathrm{s}$ wind speeds $14 \mathrm{~m}$ from the turbines was $62.0 \mathrm{dBA}$. Although these sound levels are not particularly high (the equivalent of normal conversation), Waye and Ohrstrom [30] hypothesised it is the characteristics of different wind turbine noise mechanisms not just level that may cause annoyance. This is an important point to consider because different models of wind turbine may exhibit different noise mechanisms; for example a tonal noise or intermittent sound may be considered more intrusive than a continuous or broadband sound [30].

Results of Waye and Ohrstrom's study of 25 individuals who were asked to list perceived sounds from a number of wind turbine recordings and to rate how annoying each sound was showed that sounds that were perceived more readily were also considered the most annoying; these were 'lapping', 'swishing' and 'whistling'. 'Low-frequency' and 'grinding' sounds were considered to be less obtrusive. Even though Waye and Ohrstrom's study was carried out on sounds from large scale wind turbines, it is still relevant for the current study because among the sounds most commonly reported from the results of the survey results reported in Table 2 were 'swooshing' and 'whistling'.

The ranking of the turbine sounds reported from the survey results in Table 2 is different for the $0.6 \mathrm{~kW}$ micro and the $5 \mathrm{~kW}$ small turbine types because the characteristics of the turbines vary; for example, the blade shape, the mechanism at the hub, the blade pass frequency and the method for attachment of blades. Sounds will also manifest themselves differently due to turbine sizes and rotational speeds. 
Rotational speeds are especially important for small wind systems in terms of sound characteristics, for a large scale turbine, rotational speeds are typically 16rpm whereas for micro turbines this can be up to 1250rpm. Therefore for a large scale turbine the blade pass frequency (less than 1 blade pass per second) causes discrete auditory events (often described as 'low frequency' or 'thumping') because the gap between the blade pass events are large enough that they may be perceived as independent. In the case of micro wind turbines, the blade pass frequency can be as much as 60 per second and the blade pass mechanism manifests itself as a continuous source of sound which is very much in the audible range of frequencies. The differences in blade pass frequencies can even describe sound variations between micro and small turbines. Small turbines typically rotate at around 300rpm at rated wind speed and blade pass at this rotational speed would be 15 per second, significantly lower than for a micro turbines. The lower blade pass frequency may justify why the low frequency sound is ranked higher in the reported sounds from the survey data for the small turbine type than for the micro turbine (Table 2). So as small wind turbines rotate faster, any mechanism related to the speed of rotation such as blade pass and electromechanical noise all move up the frequency spectrum.

The top perceived sound from both the $0.6 \mathrm{~kW}$ turbine type and the $5 \mathrm{~kW}$ turbine type was 'swooshing'. Swooshing is of a broadband nature and is often associated with inflow turbulence noise up to about $1000 \mathrm{~Hz}$ or turbulent boundary layer trailing edge noise where a peak frequency is usually in the range $500-1500 \mathrm{~Hz}$ [31]. The frequency spectra in Figure 3, Figure 4 and Figure 5 show increased noise levels from the turbines in these frequency regions suggesting that inflow turbulence and/or turbulent trailing noise may be present for both turbine types.

The third highest perceived sound reported from survey results from the $0.6 \mathrm{~kW}$ turbines was whistling, which is tonal in nature and is generally described as a high frequency sound. This is vastly different to the third most commonly reported sound from the $5 \mathrm{~kW}$ turbine, which was low frequency noise. The contrast in reported sounds for the two turbine types is again due to differences in design of the two turbine types. 


\section{CONCLUSIONS}

Results from a survey investigating the perceived loudness and occurrence of various sounds by respondents living close to a small or micro wind turbine have been presented.

It has been found that an individual's level of positive and negative affectivity best explain the variance in attitude to wind turbines and noise perception. Trait Neuroticism and Frustration Intolerance best explain the variance in symptom reporting. It has also been demonstrated that attitude to wind turbines has a significant effect on noise perception and that noise perception has a significant effect on symptom reporting.

The most commonly reported sounds from the survey data for the small and micro turbine types were 'swooshing', 'humming' and 'whistling', however for the 5kW turbine type 'low frequency' sounds were reported more than 'whistling'. These findings have been compared with measurements taken at two installations with examples of each turbine type with good results.

The postal questionnaire has provided insight into the relationship between perceived noise, attitude to wind turbines and symptom reporting. However the survey required that respondents provide a retrospective opinion and therefore the study is open to common method variance and retrospective bias. For that reason a longitudinal study, capturing data before and after site installation, is recommended to provide a more detailed understanding of the issues discussed in this paper, with a door-to-door data collection to improve response rate.

\section{ACKNOWLEDGEMENTS}

This research was supported under NERC award NE/C513169/1 for Phase I of the UK Energy Research Centre. 


\section{References}

1 M. Wolsink, M. Sprengers, A. Keuper, T. H.Pedersen, C. A.Westra, Annoyance from wind turbine noise on sixteen sites in three countries. in Proceedings of the European Community Wind Energy Conference. 1993. Lubeck, Travemunde.

2 E. Pedersen, F. van den Berg, R. Bakker, Response to noise from modern wind farms in The Netherlands. Journal of the Acoustical Society of America, 2009. 126(2): p. 634-643.

3 J. Taylor, The characteristics and perception of small wind system noise, $\mathrm{PhD}$ Thesis, University of Nottingham, 2011

4 N. Pierpont, Wind Turbine Syndrome: A Report on a Natural Experiment. 2009: K-Selected Books. 294.

5 L. D. Knopper, C. A Ollson, Health effects and wind turbines: A review of the literature, Enironmental Health, 2011, 10:78

6 K.P. Waye, E. Ohrstrom, Psycho-acoustic characters of relevance for annoyance of wind turbine noise. Journal of Sound and Vibration, 2002. 250(1): p. 65-73.

7 E. Pedersen, Noise annoyance from wind turbines: a review. Swedish Environmental Protection Agency, 2003. Report 5308.

8 E. Pedersen, K. Persson Waye, , Perception And Annoyance Due To Wind Turbine Noise-A DoseResponse Relationship, 2004, J. Acoust. Soc. Am. 116, 3460-3470.

9 E. Pedersen, K. Persson Waye, Wind Turbine Noise, Annoyance And Self-Reported Health And Well-Being In Different Living Environments, 2007, Occup. Environ. Med. 64, 480-486.

10 E. Pedersen, Effects Of Wind Turbine Noise On Humans, Third International Meeting On Wind Turbine Noise, Aalborg, Denmark 17-19 June 2009 
11 F. Van Den Berg, E. Pedersen, J. Bouma, R. Bakker, Wind farm perception - Visual And Acoustic Impact Of Wind Turbine Farms On Residents. (2008) Fp\&-2005-Science-And-Society-20, Specific Support Action, Project No. 044628. Www.Rug.N1/Wewi/

12 F. Van Den Berg, An Overview Of Residential Health Effects In Relation To Wind Turbine Noise, Fourth International Meeting On Wind Turbine Noise, Rome, Italy, 12-14 April 2011

13 R. Bowlder, G. Leventhall, Wind Turbine Noise, 2011, Multi-Science Publishing, ISBN 978-1$907132-30-813$

14 N.D. Weinsten, Individual differences in critical tendencies and noise annoyance. Journal of Sound and Vibration, 1980. 68: p. 241-248.

15 P. Lercher, Environmental Noise And Health: An Integrated Research Perspective. Environment International, 1996. 22: P. 117-128.

16 G. Belojevic, B. Jakovljevic, O. Aleksic, Subjective Reactions To Traffic Noise With Regard To Some Personality Traits. Environment International, 1997. 23(2): P. 221-226.

17 E. Pedersen, K.P. Waye, Wind Turbines - Low Level Noise Sources Interfering With Restoration? Environmental Research Letters, 2008. 3(1): P. 1-5.

18 P. Devine-Wright, Beyond Nimbyism: Towards An Integrated Framework For Understanding Public Perceptions Of Wind Energy. Wind Energy, 2005. 8(2): P. 125-139.

19 N. Harrington, The Frustration Discomfort Scale: Development And Psychometric Properties. Clinical Psychology \& Psychotherapy, 2005. 12(5): P. 374-387.

20 C. Lawrence, Measuring Individual Responses To Aggression-Triggering Events: Development Of The Situational Triggers Of Aggressive Responses (Star) Scale. Aggressive Behavior, 2006. 32(3): P. 241-252. 
21 International Personality Item Pool: A Scientific Collaboratory For The Development Of Advanced Measures Of Personality Traits And Other Individual Differences. 15/01/2009]; Available From: Http://Ipip.Ori.Org.

22 R.S. Wilson et al., Neuroticism, Extraversion, and Mortality In A Defined Population Of Older Persons. Psychosomatic Medicine, 2005. 67(6): P. 841-845.

23 D. Watson, L.A. Clark, A. Tellegen, Development And Validation Of Brief Measures Of Positive And Negative Affect - The Panas Scales. Journal Of Personality And Social Psychology, 1988. 54(6): P. 1063-1070.

24 Warwickshire Observatory (2011). Locality Profile, January 2011. Retrieved 27th March, 2012. Http://Www.Warwickshireobservatory.Org/Observatory/Observatorywcc.Nsf/0/5e53bdcfabA80b32 8025756a0032e300/\$File/South\%20leamington.Pdf

25 Acoustics - Attenuation Of Sound During Propagation Outdoors, Part 1: Calculation Of The Absorption Of Sound By The Atmosphere, International Organisation For Standards, ISO 9613$1: 1993,1993$.

26 Acoustics - Attenuation Of Sound During Propagation Outdoors, Part 2: General Method Of Calculation, International Organisation For Standards, ISO 9613-2:1996, 1996

27 B.G. Tabachnick, L.S. Fidell, Using Multivariate Statistics. 5th Ed2007, Boston: Pearson/Allyn \& Bacon.

28 S. Sahlqvist, Y. Song, F. Bull, E. Adams, J. Preston, D. Ogilvie, and The Iconnect Consortium (2011). Effect Of Questionnaire Length, Personalisation And Reminder Type On Response Rate To A Complex Postal Survey: Randomised Controlled Trial. Bmc Medical Research Methodology, 11, 62 (Open Access: Http://Www.Biomedcentral.Com/1471-2288/11/62)

29 B.J. Zhang, L.L. Shi, G.Q. Di, The Influence Of The Visibility Of The Source On The Subjective Annoyance Due To Its Noise. Applied Acoustics, 2003. 64(12): P. 1205-1215. 
30 J. Taylor, C. Eastwick, R. Wilson, C. Lawrence, The Influence Of Negative Oriented Personality Traits On The Effects Of Wind Turbine Noise, Personality And Individual Differences, 2012, Http://Dx.Doi.Org/10.1016/J.Paid.2012.09.018

31 K.P. Waye, E. Ohrstrom, Psycho-Acoustic Characters Of Relevance For Annoyance Of Wind Turbine Noise. Journal Of Sound And Vibration, 2002, 250(1): P. 65-73.

32 S. Wagner, R. Bareiss, G. Guidati, Wind Turbine Noise,1996, Berlin: Springer. 